\title{
CHEMOSPHERE
}

\section{Effect of earthworms (Eisenia fetida) on the fractionation and bioavailability of rare earth elements in nine Chinese soils}

\author{
Bei Wen, Ying Liu, Xiao-yu Hu, Xiao-quan Shan * \\ State Key Laboratory of Environmental Chemistry and Ecotoxicology, Research Center for Eco-Environmental Sciences, \\ Chinese Academy of Sciences, P.O. Box 2871, Beijing 100085, China
}

Received 1 November 2004; received in revised form 6 September 2005; accepted 7 September 2005

Available online 9 November 2005

\begin{abstract}
The effect of earthworm (Eisenia fetida) activity on soil $\mathrm{pH}$, dissolved organic carbon (DOC), fraction distribution pattern and bioavailability of rare earth elements (REEs) Y, La, Ce, $\mathrm{Pr}$ and $\mathrm{Nd}$ in nine Chinese soils were investigated using pot experiments. A three-step extraction procedure recommended by the European Community (Standards, Measurements and Testing Programme) was used to fractionate REEs in soils into water soluble, exchangeable and carbonate bound (B1), Fe- and Mn-oxides bound (B2) and organic matter and sulfide bound (B3). Inoculated with earthworms, the soil $\mathrm{pH}, \mathrm{DOC}$ and water-soluble rare earth elements fraction increased. A significant correlation was obtained between the increased DOC and the increased water-soluble REEs. REEs in fraction B1 increased after earthworm inoculation, while those in fraction B3 decreased. No significant differences were observed for REEs in fraction B2. The biomass and the concentrations of REEs in wheat shoots and roots increased after the treatment with earthworms. The results demonstrated that earthworm activity increased the mobility and bioavailability of REEs in soils.
\end{abstract}

(C) 2005 Elsevier Ltd. All rights reserved.

Keywords: Earthworm; Dissolved organic carbon; Fractionation; Bioavailability; Rare earth elements

\section{Introduction}

In recent years, more and more rare earth elements (REEs) enter the environment through various pathways because of the rapid increase of the exploitation of REE resources and its applications in modern industry, agriculture and everyday life. Many efforts have

\footnotetext{
${ }^{*}$ Corresponding author. Tel.: +86 106292 3560; fax: +86 10 62923563.

E-mail addresses: xiaoquan@mail.rcees.ac.cn, xq_shan1@ yahoo.com.cn (X.-q. Shan).
}

been made to understand the chemical behavior and bioavailability of REEs in the environment (Wyttenbach et al., 1998; Li et al., 1998; Zhang and Shan, 2001; Lu et al., 2003). It is well established that the physico-chemical properties of soils are the main factors controlling the mobility, transformation, and bioavailability of REEs in soils (Shan et al., 2004). The chemical fractionations afford valuable information in evaluating the bioavailability of REEs in soils (Cao et al., 2000; Wen et al., 2001).

Earthworms are ubiquitous species living in soils. Earthworm activity plays an important role in changing 
soil properties (Lee, 1985; Pallant and Hilster, 1996; Boyle et al., 1997; Capowiez et al., 2000; Ponder et al., 2000). By making burrows, earthworms greatly influence soil structure and therefore modify soil transport characteristics (Jégou et al., 2000). By ingesting organic debris, they enhance soil nutrients (for example $\mathrm{C}, \mathrm{N}$ and $\mathrm{P}$ ) availability beneficial to the plant growth. By excreting mucus and urine, they change the distribution and activity of microbes and soil biota (Binet et al., 1998; Toyota and Kimura, 2000; Salmon, 2001). Moreover, it has been reported that after treatment with earthworms, the fraction distribution of heavy metals is changed significantly, thus, affecting their bioavailability (Devliegher and Verstraete, 1996; Cheng and Wong, 2002; Ma et al., 2002). This effect was attributed (Wen et al., 2004) to the enhancement effect of dissolved organic matter. However, the effect of earthworms on the fractionation and bioavailability of REEs is still unclear.

The aim of the present study was to investigate the effect of earthworm activity on the fractionation and bioavailability of REEs. The soil $\mathrm{pH}$, DOC, REE fraction distributions and the concentrations of REEs in wheat roots and shoots with and without earthworms were compared.

\section{Materials and methods}

\subsection{Soil sample collection and preparation}

Nine Chinese cultivated soils were collected from Jiangxi Province, southern China (Yingtan soil); Beijing, northern China (Beijing soil); Hubei Province, central China (Wuhan soil), Shandong Province, eastern China (Rongcheng soil), Heilongjiang Province, northeastern China (Heilongjiang soils), Guizhou Province, southeast China (Anshun soils), Shanghai, east China (Shanghai soil), Fujian Province, southeast China (Chaozhou soil), and Shanxi Province, northern China (Changzhi soil). Soil samples were taken from the cultivated surface layer $(0-20 \mathrm{~cm})$. The soils were air-dried, ground and screened through a 1-mm nylon fiber sieve to remove stones, plant roots, and other large particles.

Soil $\mathrm{pH}$ was measured in de-ionized water-soil suspension using a ratio of $1: 1$ (w:v), organic $\mathrm{C}$ was determined by the Walkley-Black procedure (Nelson and Sommers, 1982), and cation exchange capacity (CEC) was measured by the method of Rhoades (1982). Amorphous iron (Fe) and aluminum (Al) oxides were determined by ammonium oxalate extraction method (Blakemore et al., 1987), and crystalline Fe and $\mathrm{Al}$ oxides by the oxalate-ascorbic acid extraction method of Shuman (1982). Manganese oxide content was determined by extraction with $0.1 \mathrm{~mol}^{-1}$ of hydroxyl-ammonium hydrochloride (Shuman, 1982).

\subsection{Pot experiments}

One $\mathrm{kg}$ of soil was placed in a plastic pot before planting, 12 earthworms (Eisenia fetida), purchased from China Agricultural University, $0.60 \pm 0.03 \mathrm{~g}$ fresh weights each, $3.5-4.5 \mathrm{~cm}$ in length, were inoculated in each pot under greenhouse conditions. The soils were adjusted to approximately $60 \%$ water-holding capacity, and water loss was compensated daily by addition of deionized water. Wheat seeds (Triticum aestivum L.) were thoroughly rinsed with water, and germinated on a filter paper moistened with de-ionized water, ten uniformly germinated seeds with radical emerged were sown in all soil types. A total of 20 seeds were sown per pot and subsequently reduced to 15 plants. Winter wheat in pots without earthworms served as controls. All treatments were replicated three times.

Wheat shoots and roots were harvested 6 weeks after germination. The plant shoots were cut off with a plastic knife near the soil surface and washed with dilute detergent solution followed by several rinses with de-ionized water. The roots were separated from soil by washing with de-ionized water carefully. The plant materials were dried at $70{ }^{\circ} \mathrm{C}$ for $48 \mathrm{~h}$ and the dried plant tissue was weighed and finely ground before metal determination.

The soil collected from each pot after harvest was airdried, mixed, sieved (1-mm), and then analyzed for DOC and fractionations of REEs by the three-step BCR method (Quevauviller et al., 1993).

\subsection{Water-soluble REEs and DOC}

Water-soluble REEs and DOC were obtained by shaking $1.0 \mathrm{~g}$ of dried soil with $5.0 \mathrm{ml}$ de-ionized distilled water in $50 \mathrm{ml}$ polypropylene centrifuge tubes for $24 \mathrm{~h}$. After centrifuging at $4000 \mathrm{~g}$ for $30 \mathrm{~min}$, the supernatant was filtered with $0.45 \mu \mathrm{m}$ membrane. The concentrations of REEs and the DOC in the supernatants were determined by inductively coupled plasma mass spectrometry (ICP-MS) and TOC instrument (Shimadzu 5000), respectively.

\subsection{Fractionation of REEs}

Three-stage sequential fractionation procedure proposed by the European Community (Standards, Measurements and Testing Programme, BCR) (Quevauviller et al., 1993) was carried out. The REE fractions were specified as fraction B1: water soluble, exchangeable and carbonate bound; fraction $\mathrm{B} 2$ : $\mathrm{Fe}-\mathrm{Mn}$ oxide bound; and fraction B3: organic matter and sulfide bound. Dried soil $(0.50 \mathrm{~g})$ was used for fractionation. The procedure was replicated three times for each soil sample. Following each extraction, the mixture was centrifuged at $4000 \mathrm{~g}$ for $30 \mathrm{~min}$ to separate the supernatant from the residues. The residues were washed with 
de-ionized water, and washings were combined with the supernatant fraction. The residues were then subject to the next step of BCR extraction method.

\subsection{Determination of REES}

The concentrations of REEs in wheat shoots and roots, soil and each soil fraction were determined by ICP-MS (PQ3, Fisons Instruments, UK). ${ }^{115}$ In was added as an internal standard to monitor matrix effects and signal drifting. General instrumental operating conditions and sample digestion methods have been described previously (Wen et al., 1999). The analyses were carried out in triplicate.

\subsection{Reagents and statistics}

All reagents used were of analytical reagent grade or better.

Statistical analyses were conducted with the software SPSS 11.5 for Windows (SPSS Inc. Chicago, USA). All values including soil $\mathrm{pH}$, DOC, total concentrations of REEs in soils and in soil fractions, in wheat roots and shoots, biomass of dry wheat, are reported as mean \pm standard errors. Paired-samples $t$-test analysis was performed to establish significant differences between treatments with and without earthworms.

\section{Results}

\subsection{Soil and earthworms}

The soils represented a wide range of physicochemical properties (Table 1). The REE concentrations of soils are shown in Table 2.

No mortality was observed 6 weeks after inoculation. The average fresh weight of each earthworm inoculated was $0.60 \mathrm{~g}$. After wheat shoots and roots were harvested 6 weeks after planting, still no mortality was observed,
Table 2

Total concentrations of REEs in soils $\left(\mu \mathrm{g} \mathrm{g}^{-1}\right)^{\mathrm{a}}$

\begin{tabular}{lccccc}
\hline Soils & $\mathrm{Y}$ & $\mathrm{La}$ & $\mathrm{Ce}$ & $\mathrm{Pr}$ & $\mathrm{Nd}$ \\
\hline Beijing & 12.4 & 29.8 & 62.7 & 7.21 & 27.5 \\
Yingtan & 1.53 & 4.60 & 7.50 & 0.78 & 4.20 \\
Helongjiang & 9.11 & 19.6 & 35.1 & 4.36 & 15.7 \\
Rongcheng & 19.9 & 27.2 & 33.2 & 2.93 & 8.26 \\
Wuhan & 21.7 & 35.7 & 30.1 & 3.61 & 10.3 \\
Anshun & 20.2 & 48.8 & 44.1 & 6.41 & 17.7 \\
Shanghai & 25.7 & 34.9 & 34.2 & 4.25 & 11.7 \\
Chaozhou & 28.1 & 71.9 & 35.7 & 5.68 & 20.9 \\
Changzhi & 17.9 & 31.8 & 35.2 & 4.83 & 14.6 \\
\hline
\end{tabular}

${ }^{a}$ Relative standard deviations are less than $10 \%$ for six measurements.

and the average fresh weight of each earthworm was $0.61 \mathrm{~g}$.

\subsection{Effect of earthworms on the soil pH and DOC}

The $\mathrm{pH}$ values of all soils increased from 0.2 to 1.1 units due to earthworm activity (Fig. 1). All differences were significant $(p<0.05, n=6)$ except for one soil $(p<0.1, n=6)$. The $\mathrm{pH}$ of Beijing soil was affected the most significantly since it increased from 6.9 to 8.0, while $\mathrm{pH}$ of Heiliongjiang soil was only slightly elevated from 7.3 to 7.5 .

Earthworm activity significantly $(p<0.1)$ increased DOC for all nine soils (Fig. 2). The DOC increase factors ranged from 1.23 (Chaozhou soil) to 2.50 (Changzhi soil) after the treatment with earthworms.

\subsection{Effect of earthworm activity on water-soluble REES}

The concentrations of REEs in the water-soluble fraction were compared between soils with and without earthworms (Fig. 3). Soils treated by earthworms significantly increase $(p<0.05)$ the REEs water-soluble fraction. The increase of water-soluble REEs fraction was

Table 1

Selected properties of soils

\begin{tabular}{|c|c|c|c|c|c|c|c|c|c|c|c|c|}
\hline \multirow[t]{2}{*}{ Soil } & \multirow[t]{2}{*}{ Type } & \multirow[t]{2}{*}{$\begin{array}{l}\text { Sand } \\
(\%)\end{array}$} & \multirow[t]{2}{*}{$\begin{array}{l}\text { Silt } \\
(\%)\end{array}$} & \multirow[t]{2}{*}{$\begin{array}{l}\text { Clay } \\
(\%)\end{array}$} & \multicolumn{2}{|l|}{$\begin{array}{l}\mathrm{Fe} \\
(\%) \\
\end{array}$} & \multicolumn{2}{|l|}{$\begin{array}{l}\mathrm{Al} \\
(\%) \\
\end{array}$} & \multirow[t]{2}{*}{$\begin{array}{l}\mathrm{Mn} \\
\left(\mathrm{mg} \mathrm{kg}^{-1}\right)\end{array}$} & \multirow[t]{2}{*}{$\begin{array}{l}\text { CEC } \\
\left(\mathrm{cmol} \mathrm{kg}^{-1}\right)\end{array}$} & \multirow[t]{2}{*}{$\mathrm{pH}$} & \multirow[t]{2}{*}{$\begin{array}{l}\text { Organic } \\
\text { C }(\%)\end{array}$} \\
\hline & & & & & Crystal & Amorphous & Crystal & Amorphous & & & & \\
\hline Beijing & Mollisols & 37.6 & 51.6 & 10.8 & 0.88 & 0.32 & 0.36 & 0.11 & 112 & 15.7 & 6.90 & 0.78 \\
\hline Yingtan & Ultisol & 19.5 & 38.7 & 42.4 & 3.52 & 0.72 & 1.39 & 0.28 & 27.6 & 14.2 & 4.56 & 0.89 \\
\hline Helongjiang & Mollisols & 9.8 & 62.8 & 27.4 & 1.50 & 0.40 & 1.60 & 0.34 & 326 & 26.0 & 7.35 & 3.71 \\
\hline Rongcheng & Mollisols & 89.7 & 3.91 & 6.40 & 11.7 & 0.33 & 0.97 & 0.011 & 475 & 9.82 & 6.08 & 0.39 \\
\hline Wuhan & Alfisol & 52.9 & 21.4 & 25.7 & 23.5 & 0.73 & 1.05 & 0.012 & 409 & 22.8 & 6.73 & 1.72 \\
\hline Anshun & Cambisols & 37.2 & 32.8 & 30.1 & 0.62 & 0.42 & 0.14 & 0.13 & 103 & 51.3 & 6.29 & 6.76 \\
\hline Shanghai & Luvisols & 21.4 & 65.5 & 13.2 & 1.23 & 0.29 & 0.43 & 0.35 & 26.1 & 36.6 & 5.53 & 3.02 \\
\hline Chaozhou & Ferralisols & 29.6 & 33.7 & 36.7 & 1.99 & 4.43 & 0.60 & 0.046 & 107 & 18.1 & 5.96 & 1.81 \\
\hline Changzhi & Luvisols & 24.6 & 52.3 & 18.1 & 0.55 & 0.34 & 0.77 & 0.71 & 50.8 & 21.9 & 7.29 & 4.12 \\
\hline
\end{tabular}




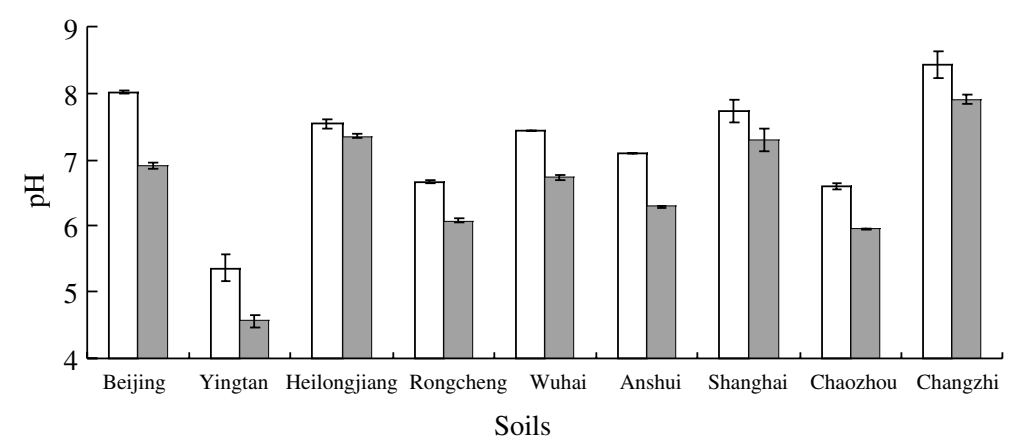

Fig. 1. Effects of earthworm activity on soil pH. White column: earthworms; black column: no earthworms; bars represent standard errors.

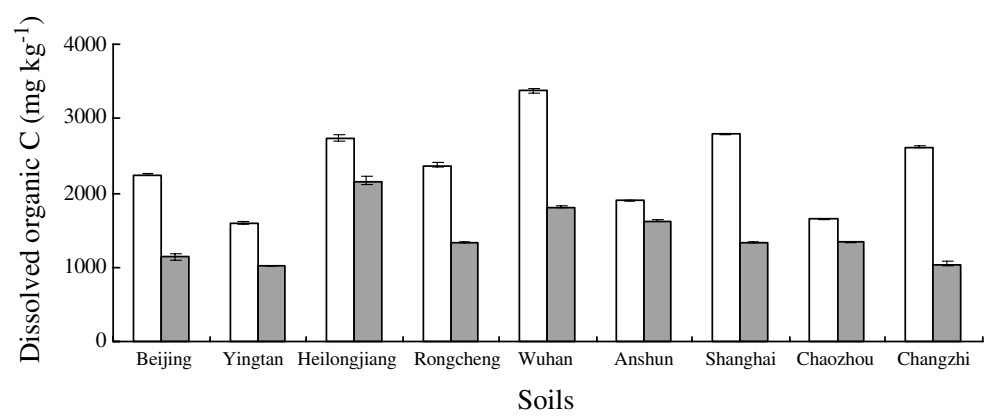

Fig. 2. Effects of earthworm activity on soil DOC. White column: earthworms; dark column: no earthworms; bars represent standard errors.

the greatest in Changzhi soil (Fig. 3i) and the lowest in the Heilongjiang soil (Fig. 3c).

\subsection{Effect of earthworms on the REE fraction distribution}

The soils with and without earthworms were subjected to $\mathrm{BCR}$ sequential extraction, and the distributions patterns of REEs among B1, B2 and B3 fractions were compared in order to investigate their binding site shift. For the nine soils studied, REEs increased in B1 $(p<0.1)$ by factor of 1.3-2.9, 1.2-5.2, 1.2-3.7, 1.3-3.0 and 1.1-2.2 for $\mathrm{Y}, \mathrm{La}, \mathrm{Ce}, \mathrm{Pr}$ and $\mathrm{Nd}$, respectively, while those in B3 decreased $(p<0.1)$ by $21-44 \%, 15-44 \%, 12-42 \%$, $14-40 \%$, and $17-51 \%$, respectively, after earthworm treatment. No significant changes in $\mathrm{B} 2$ fraction of REEs were found $(p>0.1)$. Since the presence of earthworms had a similar effect on the distribution of $\mathrm{Y}, \mathrm{La}, \mathrm{Ce}, \mathrm{Pr}$ and $\mathrm{Nd}$ among three fractions B1, B2 and B3, only La results were displayed graphically in Fig. 4.

\subsection{Relationship between DOC and water-soluble REEs}

The comparison between the DOC and REE contents of the water-soluble fraction can provide an evidence for the effect of DOC on the solubility of REEs. We calculated the ratios of $\mathrm{DOC}_{\text {earthworms }}$ to $\mathrm{DOC}_{\text {no earthworms }}$ and the ratios of the Water-soluble

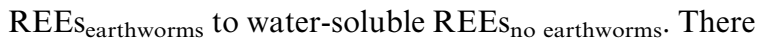
were strongly positive correlations $(p<0.01)$ between the $\mathrm{DOC}_{\text {earthworms }} / \mathrm{DOC}_{\text {no earthworms }}$ values and the watersoluble REEs earthworms/water-soluble REEs $_{\text {no earthworms }}$ values. The correlation coefficients of $\mathrm{Y}, \mathrm{La}, \mathrm{Ce}, \mathrm{Pr}$, and $\mathrm{Nd}$ were $0.98,0.92,0.92,0.93$, and 0.91, respectively.

\subsection{Effects of earthworms on wheat biomass and REE accumulation in wheat roots and shoots}

Earthworm treatments significantly increased the yield of wheat shoots and roots by 1.2-1.6 and 1.51.9 times, respectively, in the nine soils $(p<0.1)$. The mean and range of REEs in wheat roots and shoots with and without earthworms are given in Table 3. The REE concentrations of wheat roots in nine soils increased by $27-53 \%, 25-61 \%, 16-33 \%, 18-45 \%$ and $30-76 \%$ for $\mathrm{Y}, \mathrm{La}, \mathrm{Ce}, \mathrm{Pr}$ and $\mathrm{Nd}$ in the presence of earthworms, respectively $(p<0.1)$, while REEs in wheat shoots increased by $15-39 \%, 13-34 \%, 12-26 \%, 16-31 \%$ and $19-50 \%$ for $\mathrm{Y}, \mathrm{La}, \mathrm{Ce}, \mathrm{Pr}$ and $\mathrm{Nd}$, respectively $(p<0.1)$. 

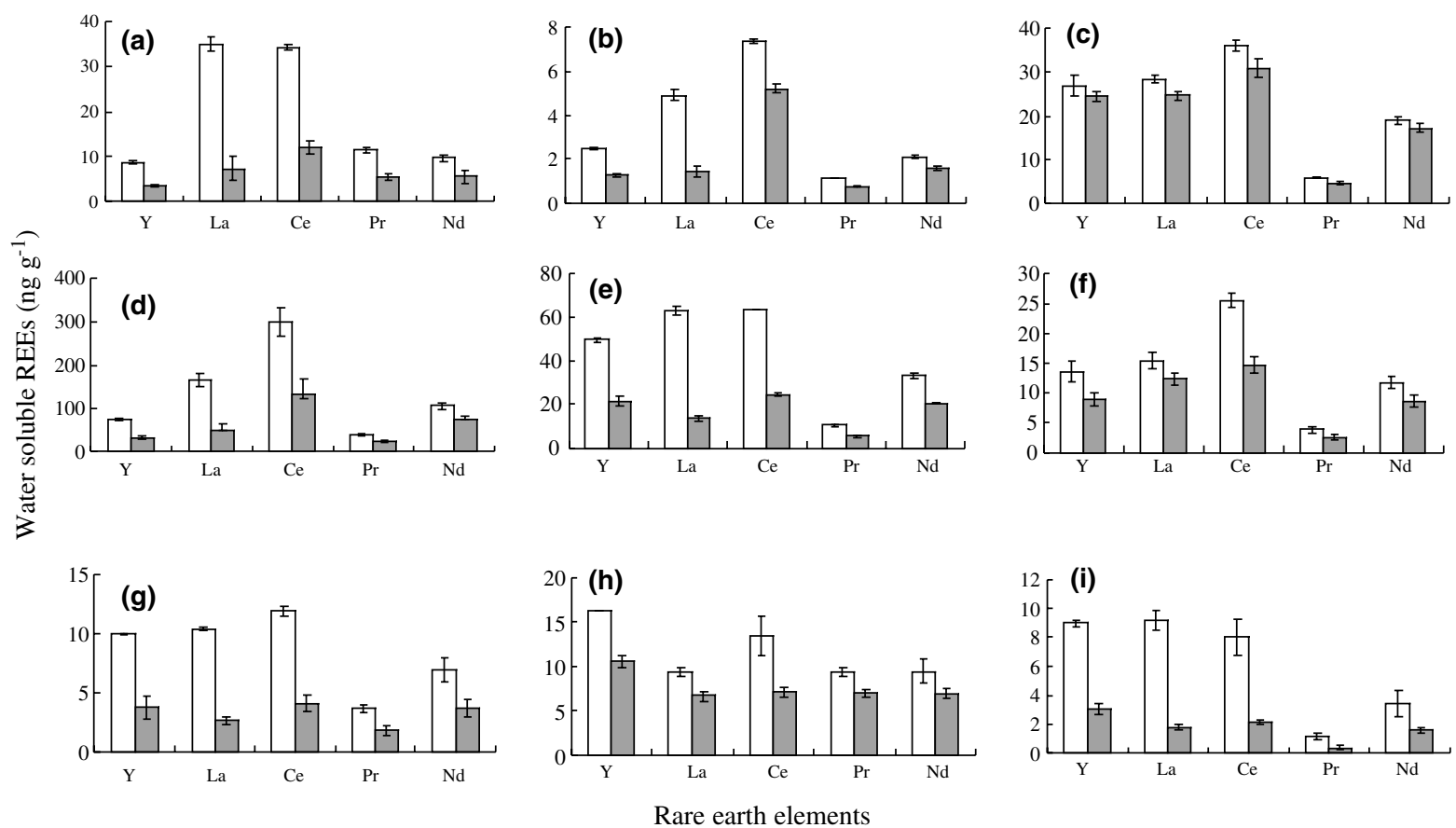

Fig. 3. Effect of earthworm activity on the concentrations of water-soluble REEs. White column: earthworms; dark column: no earthworms; bars represent standard errors: (a) Beijing soil, (b) Yingtan soil, (c) Heilongjiang soil, (d) Rongcheng soil, (e) Wuhan soil, (f) Anshun soil, (g) shanghai soil, (h) Chaozhou soil and (i) Changzhi soil.

\section{Discussion}

It is well established that soil $\mathrm{pH}$ is a key factor affecting the adsorption-desorption behaviors and hence bioavailability of REEs (Cao et al., 2001; Li et al., 2001; Wen et al., 2002). Therefore, it is important to determine the $\mathrm{pH}$ change due to the earthworm activity. The increasing soil $\mathrm{pH}$ was attributed to the increase $\mathrm{N}$ associated excreta by earthworm such as alkaline urine (Parkin and Berry, 1999; Salmon, 2001). Another explanation for the increasing $\mathrm{pH}$ could be earthworm calciferous glands (Lee, 1985). Regardless of the precise mechanism, it seems likely that the earthworms play an active role in $\mathrm{pH}$ regulation of the soil.

Generally, increased soil $\mathrm{pH}$ leads to the enhancement of the affinity of soils for REEs due to $\mathrm{pH}$-dependent surface-charge density on colloids, resulting in the less concentration of REEs in soil solution (Cao et al., 2001; Shan et al., 2002). However, this phenomenon was not observed in our experiments. Instead, the treatment with earthworms elevated the water-soluble REEs (Fig. 3). In view of the increase of soil $\mathrm{pH}$ and the elevation of water-soluble REEs, one may deduce that there must be some REE-chelating metallophores produced by earthworm.

It is well documented that earthworm activity improves soil properties through physical, chemical, bio- logical and biochemical mechanisms, such as enhances the fragmentation and humification of coarse particulate organic matter into finer fractions and influences the distribution of organic matter in soil (Martin, 1991). Parkin and Berry (1999) found that the DOC in burrow soil was much higher than that in nonburrow soil. Jones (1997) observed that there was a strong relationship between the large amount of DOC and the desorption amount of REEs. He suggested that DOC may be able to bind REEs in solution, thereby increasing REE desorption to the water phase. Moreover, DOC could enhance the bioaccumulation of REEs in wheat roots and shoots significantly ( $\mathrm{Gu}$ et al., 2001). The positive relationship between water-soluble REEs and DOC revealed the basic mechanisms of how earthworms affected the behaviors of REEs in soils.

In addition, the fragmentation was also associated with microbes, whose population and activity were increased by earthworms (Toyota and Kimura, 2000; Binet et al., 1998). Results obtained by our previous experiments showed that in the presence of earthworms, the population of bacteria, actinomycetes and fungus in Beijing soil were much higher than those in the absence of earthworms (Wen et al., 2004). These microbes can exudate some low-molecular-weight organic acids, such as acetic, citric and oxalic acids (Jones, 1998), which could enhance the supply of 

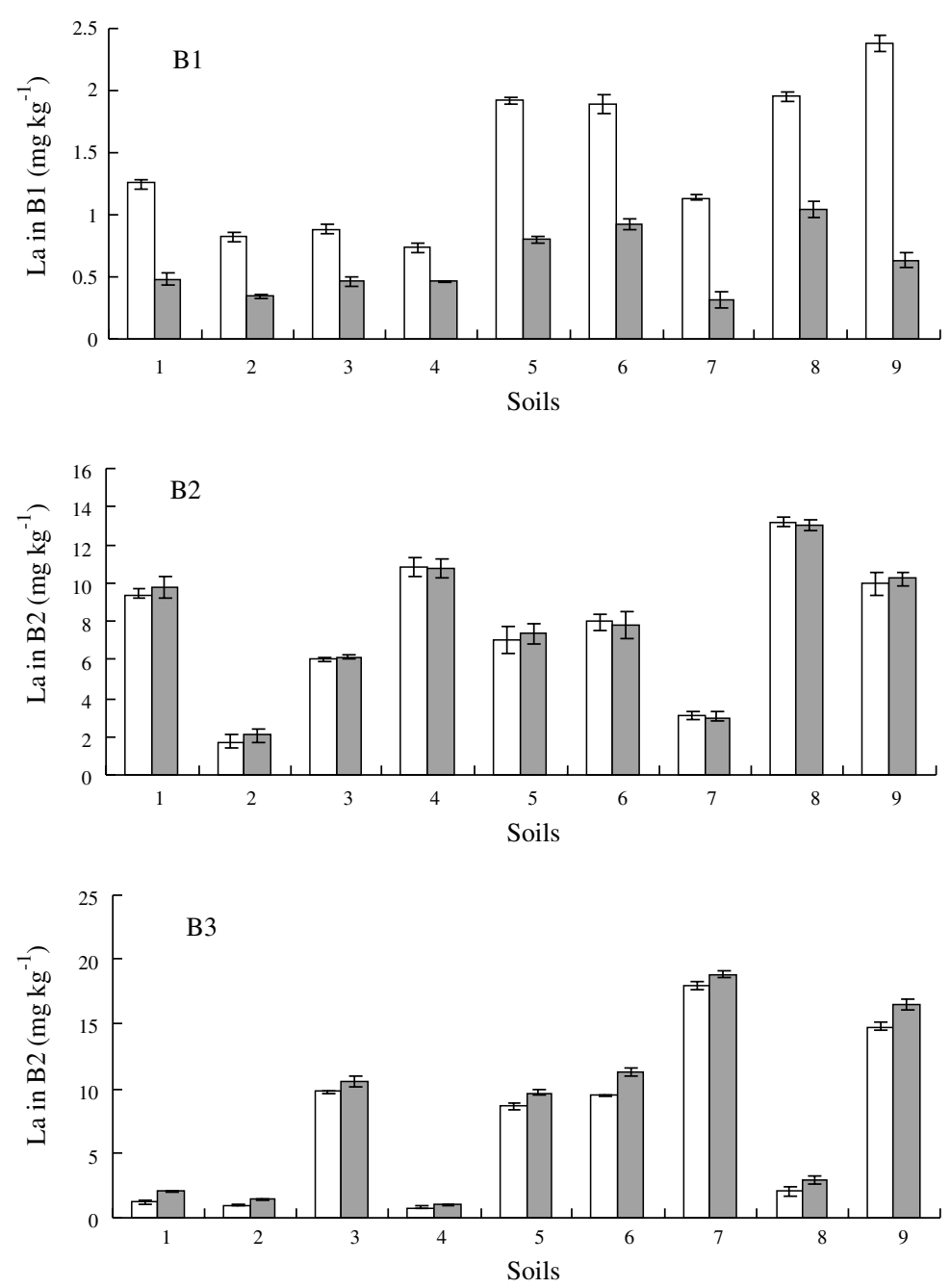

Fig. 4. Effect of earthworm activity on the fraction distribution pattern of La in B1, B2 and B3 in nine soils. White bar: earthworms; dark bar: no earthworms; bars represent standard errors: (1) Beijing, (2) Yingtan, (3) Heilongjiang, (4) Rongcheng, (5) Wuhan, (6) Anshun, (7) Shanghai, (8) Chaozhou and (9) Changzhi soil.

Table 3

Mean and range of REEs in wheat grown in all nine soils with and without earthworm treatments

\begin{tabular}{|c|c|c|c|c|c|c|c|c|}
\hline \multirow[t]{4}{*}{ Element } & \multicolumn{8}{|c|}{ Concentration of REEs in roots and shoots $\left(\mu \mathrm{g} \mathrm{g}^{-1}\right)$} \\
\hline & \multicolumn{4}{|c|}{ In roots } & \multicolumn{4}{|c|}{ In shoots } \\
\hline & \multicolumn{2}{|c|}{ With earthworms } & \multicolumn{2}{|c|}{ Without earthworms } & \multicolumn{2}{|c|}{ With earthworms } & \multicolumn{2}{|c|}{ Without earthworms } \\
\hline & Mean & Range & Mean & Range & Mean & Range & Mean & Range \\
\hline $\mathrm{Y}$ & 3.61 & $0.98-6.12$ & 2.55 & $0.77-4.01$ & 0.22 & $0.07-0.39$ & 0.17 & $0.05-0.30$ \\
\hline $\mathrm{La}$ & 5.48 & $0.85-9.25$ & 3.40 & $0.67-8.26$ & 0.35 & $0.22-0.56$ & 0.21 & $0.20-0.49$ \\
\hline $\mathrm{Ce}$ & 13.6 & $5.01-18.1$ & 10.2 & $3.98-16.1$ & 0.58 & $0.30-1.27$ & 0.42 & $0.26-1.09$ \\
\hline $\operatorname{Pr}$ & 1.61 & $1.01-2.99$ & 1.11 & $0.93-1.51$ & 0.08 & $0.05-1.01$ & 0.05 & $0.03-0.80$ \\
\hline $\mathrm{Nd}$ & 3.54 & $1.69-7.34$ & 2.01 & $0.98-5.68$ & 0.21 & $0.15-0.46$ & 0.13 & $0.10-0.38$ \\
\hline
\end{tabular}

REEs to roots (Shan et al., 2002), and enhance the uptake of REEs by plants (Han et al., 2005). Such, exudation of microbe is an important source of metallophores. 
Information of the REE binding site shift can help to understand the REE behavior as affected by earthworms. The increase in REE concentrations in B1 and the decrease in $\mathrm{B} 3$ fractions suggested that the distribution pattern of REEs among different fractions was changed due to earthworm activity. One of the DOC sources is the decomposition of soil organic matter by earthworms and microbes. Since B1 represented the most bioavailable form of REEs to plants ( $\mathrm{Li}$ et al., 1998; Wang et al., 2001), we hypothesized that earthworm treatments increased the bioavailability of REEs in soils.

Earthworm activity improves nutrient mineralization, which also benefits to plants. The results obtained by Pallant and Hilster (1996) showed that the presence of earthworms significantly increased the yields of plants, which is in agreement with our results. Furthermore, the concentrations of $\mathrm{La}, \mathrm{Ce}, \mathrm{Pr}$ and $\mathrm{Nd}$ in both wheat roots and shoots with earthworm treatments were significantly higher than those without earthworm treatments, which demonstrated that earthworms could enhance the bioavailability of REEs.

Although in this study, we proved that the earthworm activity could increase the disassociation and bioavailability of REEs by enhancing the DOC, it should be mentioned that the $\mathrm{pH}, \mathrm{DOC}$, and water-soluble REEs were determined after soil mixing and extraction. No efforts were made to distinguish the earthworm cast and drilosphere soil from bulk soil. There is also no information if the increased DOC is the result of the earthworm activity or soil microorganism activation. In addition, our study was based on the inoculation of 12 earthworms for 12 weeks in $1 \mathrm{~kg}$ soil and the soil moisture was maintained at $60 \%$ water-holding capacity. Higher earthworm density may lead to higher metabolic rates of the microflora community and higher production of dissolved organic matter. Besides, it is reported that microbial activity, nutrient and $\mathrm{C}$ mineralization were increased in earthworm casts over the period of a few days, but after drying out and remaining stable for a few months or years, the same casts had lower microbial activity and $\mathrm{C}$ mineralization rate (Brown et al., 2000). Therefore, the long-term consequences should be considered too.

\section{Conclusion}

It was demonstrated that the soil $\mathrm{pH}, \mathrm{DOC}$ and water-soluble REEs are increased by earthworm activities. The decrease of $\mathrm{B} 3$ form, the increase of $\mathrm{B} 1$ form, and a simple relationship between DOC and water-soluble REEs indicated that earthworm activity could increase the bioavailability of REEs by decomposing organic matter into smaller components. These results revealed that earthworm activity is an important factor that affected the fractions distribution pattern, mobility and bioavailability of REEs in soil.

\section{Acknowledgement}

This study was supported by the National Natural Science Foundation of China (Grant Number: 20237010).

\section{References}

Binet, R., Fayolle, L., Pussard, M., 1998. Significance of earthworms in stimulating soil microbial activity. Biol. Fertil. Soils 27, 79-84.

Blakemore, L.C., Searle, P.L., Daly, B.K., 1987. Methods for chemical analysis of soils. New Zealand Bureau Scientific Report No. 80. NZ Soil Bureau, Lower Hutt, New Zealand.

Boyle, K.E., Curry, J.P., Farrell, E.P., 1997. Influence of earthworms on soil properties and grass production in reclaimed cutover peat. Biol. Fertil. Soils 25, 20-26.

Brown, G.G., Barois, I., Lavelle, P., 2000. Regulation of soil organic matter dynamics and microbial activity in the drilosphere and the role of interactions with other edaphic functional domains. Eur. J. Soil Biol. 36, 177-198.

Cao, X., Wang, X., Zhao, G., 2000. Assessment of the bioavailability of rare earth elements in soils by chemical fractionation and multiple regression analysis. Chemosphere 40, 23-28.

Cao, X., Chen, Y., Wang, X., Deng, X., 2001. Effects of redox potential and $\mathrm{pH}$ value on the release of rare earth elements from soil. Chemosphere 44, 655-661.

Capowiez, Y., Pierret, A., Monestiez, P., Belzunces, L., 2000. Evolution of burrow systems after the accidental introduction of a new earthworm species into a Swiss pre-alpine meadow. Biol. Fertil. Soils 31, 494-500.

Cheng, J., Wong, M.H., 2002. Effects of earthworms on $\mathrm{Zn}$ fractionation in soils. Biol. Fertil. Soils 36, 72-78.

Devliegher, W., Verstraete, W., 1996. Lumbricus terrestris in a soil core experiment: effects of nutrient-enrichment processes (NEP) and gut-associated processes (GAP) on the availability of plant nutriments and heavy metals. Soil Biol. Biochem. 28, 489-496.

Gu, Z.M., Wang, X.R., Gu, X.Y., Cheng, J., Wang, L.S., Dai, L.M., Chen, Y.J., 2001. Effects of fulvic acid on the bioavailability of rare earth elements and GOT enzyme activity in wheat (Triticum aestivum). Chemosphere 44, 545551.

Han, F., Shan, X.Q., Zhang, J., Xie, Y.N., Pei, Z.G, Zhang, S.Z., Zhu, Y.G, Wen, B., 2005. Organic acids promote the uptake of lanthanum by barley roots. New Phytol. 165, 481492.

Jégou, D., Cluzeau, D., Hallaire, V., Balesdent, J., Trehen, P., 2000. Burrowing activity of the earthworms Lumbricus terrestris and Aporrectodea giardi and consequences on C transfers in soil. Eur. J. Soil Biol. 36, 27-34.

Jones, D.L., 1997. Trivalent metal (Cr, Y, Rh, La, Pr, Gd) sorption in two acid soils and its consequences for bioremediation. Euro. J. Soil Sci. 48, 697-702. 
Jones, D.L., 1998. Organic acids in the rhizosphere - a critical review. Plant Soil 205, 25-44.

Lee, K.E., 1985. Earthworms: Their Ecology and Relationships with Soils and Land Use. Academic Press, Sydney.

Li, B.C., Huang, S.B., Wang, W.H., Peng, A., 2001. Study on the kinetics of cerium(III) adsorption-desorption on different soils of China. Chemosphere 44, 663-669.

Li, F.L., Shan, X.Q., Zhang, T.H., Zhang, S.Z., 1998. Evaluation of plant availability of rare earth elements in soils by chemical fractionation and multiple regression analysis. Environ. Pollut. 102, 269-277.

Lu, A.X., Zhang, S.Z., Shan, X.Q., Wang, S.X., Wang, Z.W, 2003. Application of microwave extraction for the evaluation of bioavailability of rare earth elements in soils. Chemosphere 53, 1067-1075.

Ma, Y., Dickinson, N.M., Wong, M.H., 2002. Toxicity of $\mathrm{Pb} / \mathrm{Zn}$ mine tailings to the earthworm Pheretima and the effects of burrowing on metal availability. Biol. Fertil. Soils 36, 79-86.

Martin, A., 1991. Short and long term effects of the endogenic earthworm Millsonia anomalia (Megascolecidae, Oligochaeta) of tropical savannas, on soil organic matter. Biol. Fertil. Soils 11, 234-238.

Nelson, D.W., Sommers, L.E., 1982. Total carbon, organic carbon, and organic matter. In: Page, A.L. et al. (Eds.), Methods of Soil Analysis: Part 2, second ed. American Society of Agronomy, Madison, WI, pp. 539-579.

Pallant, E., Hilster, L.M., 1996. Earthworm response to 10 weeks of incubation in a pot with acid mine spoil, sewage sludge, and lime. Biol. Fertil. Soils 22, 355-358.

Parkin, T.B., Berry, E.C., 1999. Microbial nitrogen transformations in earthworm burrows. Soil Biol. Biochem. 17651771.

Ponder Jr., F., Li, F., Jordan, D., Berry, E.G., 2000. Assessing the impact of Diplocardia ornata on physical and chemical properties of compacted forest soil in microcosms. Biol. Fertil. Soils 32, 166-172.

Quevauviller, P., Rauret, G., Griepink, B., 1993. Single and sequential extraction in sediments and soils. Int. J. Environ. Anal. Chem. 51, 231-235.

Rhoades, J.D., 1982. Cation-exchange capacity. In: Page, A.L. et al. (Eds.), Methods of Soil Analysis: Part 2, second ed. American Society of Agronomy, Madison, WI, pp. 149-157.
Salmon, S., 2001. Earthworm excreta (mucus and urine) affect the distribution of springtails in forest soils. Biol. Fertil. Soils 34, 304-310.

Shan, X.Q., Lian, J., Wen, B., 2002. Effect of organic acids on adsorption and desorption of rare earth elements. Chemosphere 47, 701-710.

Shan, X.Q., Zhang, S.Z., Wen, B., 2004. Fractionation and bioavailability of rare earth elements in soils. In: Shtangeeva, I. (Ed.), Trace and Ultratrace Elements in Plants and Soil. WIT Press, Southampton, UK, pp. 249-285.

Shuman, L.M., 1982. Separating soil iron-and manganese-oxide fractions from microelement analysis. Soil Sci. Soc. Am. J. 46, 1099-1102.

Toyota, K., Kimura, M., 2000. Microbial community indigenous to the earthworm Eisenia foetida. Biol. Fertil. Soils 31, 187-190.

Wang, Z.W., Shan, X.Q., Zhang, S.Z., 2001. Comparison of speciation and bioavailability of rare earth elements between wet rhizosphere soil and air-dried bulk soil. Anal. Chim. Acta 441, 147-156.

Wen, B., Shan, X.Q., Xu, S.G., 1999. Preconcentration of ultratrace rare earth elements in seawater with 8-hydroxyquinoline immobilized polyacrylonitrile hollow fiber membrane for determination by inductively coupled plasma mass spectrometry. Analyst 124, 621-626.

Wen, B., Yuan, D.A., Shan, X.Q., Li, F.L., Zhang, S.Z., 2001. The influence of rare earth element fertilizer application on the distribution and bioaccumulation of rare earth elements in plants under field conditions. Chem. Speciation Bioavailability $13,39-48$.

Wen, B., Shan, X.Q., Lin, J.M., Tang, G.G., Bai, N.B., Yuan, D.A., 2002. Desorption kinetics of yttrium, lanthanum, and cerium from soil. Soil Sci. Soc. Am. J. 66, 1198-1206.

Wen, B., Hu, X.Y., Liu, Y., Wang, W.S., Feng, M.H., Shan, X.Q., 2004. The role of earthworms (Eisenia fetida) in influencing bioavailability of heavy metals in soils. Biol. Fertil. Soils 40, 181-187.

Wyttenbach, A., Furrer, V., Schleppi, P., Tobler, L., 1998. Rare earth elements in soil and in soil-grown plants. Plant Soil 199, 267-273.

Zhang, S.Z., Shan, X.Q., 2001. Speciation of rare earth elements in soil and accumulation by wheat with rare earth fertilizer application. Environ. Pollut. 112, 395-405. 